\title{
The Siberian moth (Dendrolimus sibiricus), a pest risk assessment for Norway
}

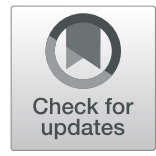

Daniel Fl $\varnothing^{1,2^{*}}$, Trond Rafoss ${ }^{1,2}$, Michael Wendell ${ }^{2}$ and Leif Sundheim ${ }^{1}$

\begin{abstract}
Background: The Siberian moth (Dendrolimus sibiricus) is a serious pest of conifers in Russia, Northern Kazakhstan, Mongolia and China. The western border of the pest's distribution in Russia is disputed, but it is present west of the 60th meridian east. The pest has the potential to defoliate a wide range of conifers.

Results: The pest is not present in Norway or other European countries, except Russia. Natural spread and human mediated transport are potential pathways for the pest. Human mediated pathways considered are: Living trees for planting, coniferous wood in the rough and foliage and branches. There has been no import of living trees from Russia to Norway during the past 30 years, and there is currently no import of coniferous wood commodities containing bark from areas, where D. sibiricus occurs.

Conclusions: The probability of $D$. sibiricus entry by natural spread is unlikely, mainly because of the geographical distance and the partial sea barriers between Norway and the infested areas. The probability of entry by human mediated pathways is unlikely due to the very limited volume of the import. Should the pest enter Norway, the probability of establishment and spread is unlikely, due to the suboptimal climatic conditions, and the fact that the two dominant conifers in the country, Norway spruce (Picea abies) and Scots pine (Pinus sy/vestris), are intermediate and poor hosts, respectively. The potential damage, should D. sibiricus enter Norway, is considered low.
\end{abstract}

Keywords: Lepidoptera, Invasive species, Geographical distribution, Forest pest

\section{Background}

The Siberian lappet moth Dendrolimus sibiricus Chetverikov 1908 is closely related to the pine-tree lappet moth Dendrolimus pini L 1758, which is present in Norway and the rest of Europe. Dendrolimus sibiricus is the most destructive pest of conifers in Russia, parts of Northern Kazakhstan, Mongolia and China (EPPO 2005). In an area stretching from the Pacific Ocean, across Russia and past the Ural Mountains conifers are infested with $D$. sibiricus (Fig. 1). During the period 1994-96 D. sibiricus damaged 700.000 ha of pine forest in Krasnoyarsk krai, Central Siberia (Zhirin et al. 2016). Between 1954 and 1957, the pest damaged over 1.5

\footnotetext{
* Correspondence: floedaniel@gmail.com

'Norwegian Institute of Bioeconomy Research, Høgskoleveien 7, 1433 Ås, Norway

${ }^{2}$ The Norwegian Scientific Committee for Food and Environment, Sandakerveien 24 C, 0473 Oslo, Norway
}

(c) The Author(s). 2020 Open Access This article is licensed under a Creative Commons Attribution 4.0 International License which permits use, sharing, adaptation, distribution and reproduction in any medium or format, as long as you give appropriate credit to the original author(s) and the source, provide a link to the Creative Commons licence, and indicate if changes were made. The images or other third party material in this article are included in the article's Creative Commons licence, unless indicated otherwise in a credit line to the material. If material is not included in the article's Creative Commons licence and your intended use is not permitted by statutory regulation or exceeds the permitted use, you will need to obtain permission directly from the copyright holder. To view a copy of this licence, visit http://creativecommons.org/licenses/by/4.0/. 


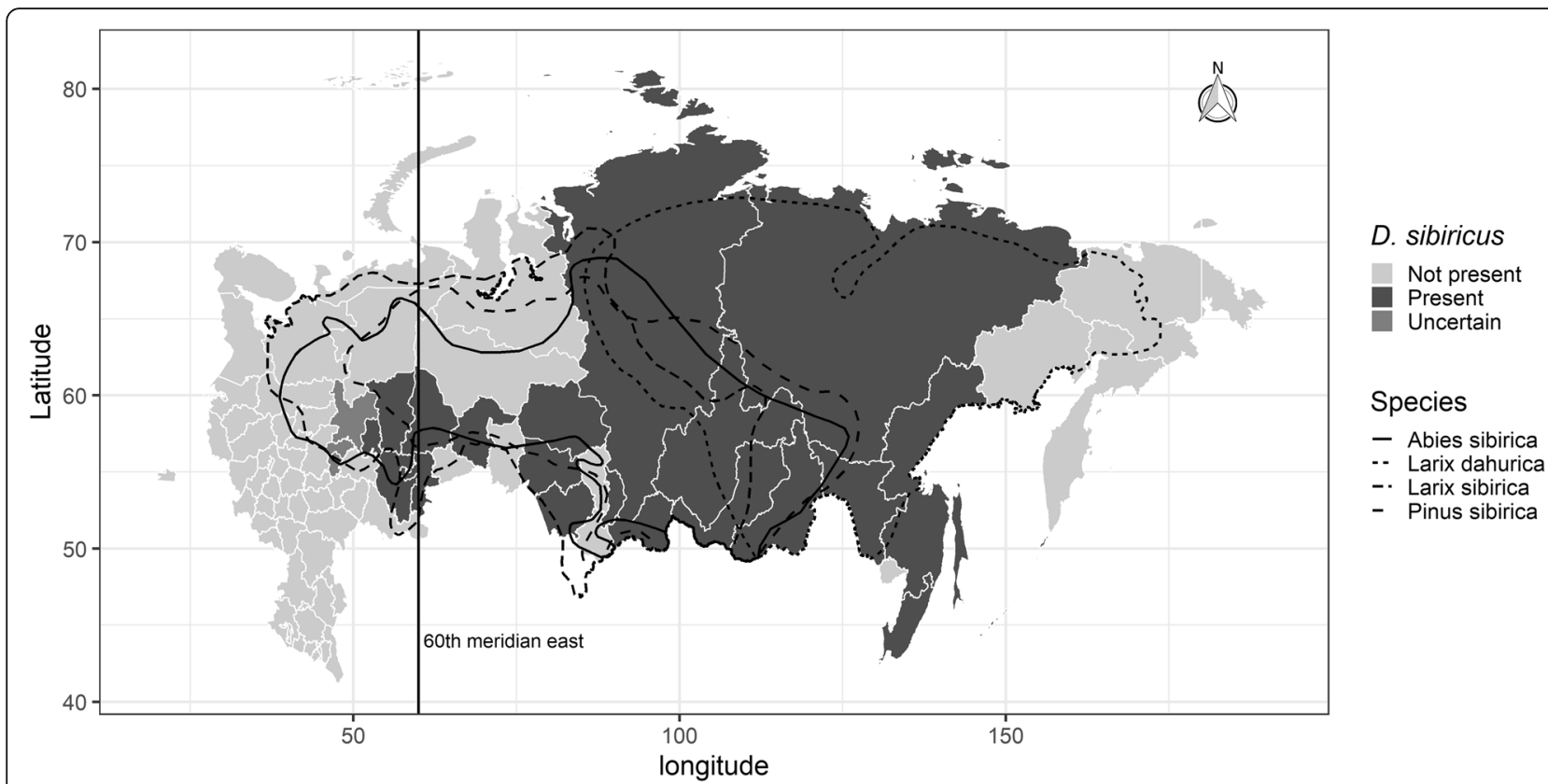

Fig. 1 Map of Russia showing the federal subjects, where Dendrolimus sibiricus is present (dark gray areas) and not present (light gray areas). The distribution of D. sibiricus is uncertain for some of the federal subjects in European Russia (gray areas). The black lines represent the distribution for some of the main host species for D. sibiricus. The 60th meridian east represents the border between Europe and Asia. The map was compiled from literature and personal communication. Data on the distribution of Picea obovata were unavailable

sibiricus fly from the end of June to the beginning of August, and each female can lay up to 800 eggs (length $1.9-2.2 \mathrm{~mm}$ ) on the bark of stems and branches and on needles of host trees (EPPO 2005). Larvae (length 60-82 $\mathrm{mm}$ ) hatch after 13 to 22 days and start feeding on the needles. Overwintered larvae make cocoons during the period June to late July and pupate (pupae $50-110 \mathrm{~mm}$ in length) in the trees. The life cycle typically takes from 1 to 2 years, depending on population density and temperature. Larvae may have between six and eight instars, and diapausing larvae survive one or two winters in the ground, in litter or underneath moss. However, parts of the larval population can enter summer diapause (a period of slow development of the third to fifth instar larvae), if food availability is low or abiotic conditions are unfavourable, prolonging their life cycle up to 4 years (Kirichenko et al. 2011). Due to this prolonged diapause, parts of the population may have a life cycle of either 2, 3 or 4 years, which contributes to the population persistence during unfavourable conditions.

\section{Host plants of the pest}

Dendrolimus sibiricus larvae only infest coniferous trees. Hardin and Suazo (2012) presented an extensive list of reported host plant species for D. sibiricus. The main hosts are Siberian fir (Abies sibirica Gordon), Siberian larch (Larix sibirica Ledeb.), Siberian spruce (Picea obovata Ledeb.) and Siberian pine (Pinus sibirica Du Tour). Kirichenko et al. (2009) concluded that D. sibiricus is able to develop on the main European coniferous hosts, potentially resulting in severe damage to large forest areas.

\section{Host plants of the pest in the PRA area}

Picea abies (L.) H. Karst. and Pinus sylvestris L. are the dominant conifers in Norwegian forests. A larval host plant bioassay showed that $D$. sibiricus larvae are able to develop on the main European coniferous hosts (Kirichenko et al. 2009). However, P. abies and P. sylvestris are intermediate and poor hosts for $D$. sibiricus larvae, respectively. On these hosts larvae development time increased, and larvae mortality reached $14.5 \%$ on $P$. abies and $66.7 \%$ on P. sylvestris, compared to $3.2 \%$ mortality on Larix decudia Mill., which had the lowest larvae mortality in the experiment (Kirichenko et al. 2009). In Norway, the main hosts of $D$. sibiricus (A. sibirica, L. sibirica, P. obovata and P. sibirica) are planted only on a very small scale, mostly in mountain forests and in the north of the country (Elven 2005). These hosts are not considered further in this assessment.

\section{Geographical distribution of the pest}

Dendrolimus sibiricus is native to Russia and restricted parts of northern Kazakhstan, Mongolia and China (EPPO 2005). The pest is present west of the 60th meridian in European Russia. However, the exact western border of $D$. sibiricus geographical distribution is disputed among experts Gninenko and Orlinskii (2002), Kirichenko et al. (2009), Kononov et al. (2016). The alleged westward expansion towards Moscow Gninenko and Orlinskii (2002) has 
been questioned (Mikkola and Ståhls 2008), and thought to be based on a misidentification of $D$. pini as D. sibiricus (Baranchikov et al. 2006). The northern limit of the pest is uncertain, but according to Rozkov (1963) the city of Yakutsk, $450 \mathrm{~km}$ south of the Arctic Circle in East Siberia, is the northernmost record of the species. However, there are uncertainties as to which data Rozkov (1963) used for his map. Therefore, $D$. sibiricus could be more widespread in Northern Russia than previously reported (Flament et al. 2013). Also, there are uncertainties as to the southern limits for the distribution of the pest in China, Mongolia and Kazakhstan. Therefore, the distribution of the main hosts in Asia may be the best indicator of the historic distribution of D. sibiricus (Fig. 1).

\section{Regulatory status of the pest}

Dendrolimus sibiricus is not regulated in the PRA area, but the pest is on the EPPO A2 List of pests recommended for regulation as quarantine pests. The pest is included in the European Union Directive 2000/29 Annex I/AI, which requires a phytosanitary certificate issued by Russia, to ensure that plants and plant products are inspected and found free from $D$. sibiricus (Council Directive 2000/29/EC 2000). It is prohibited to import into Norway coniferous plants for planting, wood with bark, chips of wood with bark, isolated bark and wood waste of conifers from NonEuropean countries and Portugal (Norwegian Ministry of Agriculture and Food 2018).

\section{Conclusions from previous Pest risk assessments}

EPPO (1998) concluded that D. sibiricus threatens large areas of coniferous forests in northern and central Europe, with the potential to cause serious and destructive epidemics. A PRA by EPPO (2000) concluded that the entry of $D$. sibiricus into the EPPO region is more likely to occur by natural spread and import of untreated wood with bark, dunnage or packing material, and less likely to occur with import of host plants for planting and cut branches. EPPO (2000) concluded that there is high probability of $D$. sibiricus establishment in the EPPO region. The potential impact within the EPPO region was considered to be high, including both direct damage to coniferous plantations and forests (mainly Abies spp., Larix spp., Picea spp., and Pinus spp.) resulting in wood losses, environmental damage to natural forests, including deforestation over large areas and social damage to people living in the damaged areas (EPPO 2000).

In a PRA for Poland, Kubasik et al. (2017) concluded that $D$. sibiricus poses a potentially very high threat to the domestic forests, because of the high proportion of coniferous trees, and if the pest enters Poland, suitable climatic conditions facilitate establishment of the pest.
However, due to limited import of relevant coniferous commodities to Poland, the probability of introduction was considered low (Kubasik et al. 2017).

A Pest Categorization of $D$. sibiricus by EFSA Panel on Plant Health (EFSA 2018) stated that the previous contradictory studies regarding the climatic requirements of $D$. sibiricus make the issue of its establishment in most of Europe uncertain, although the host plants are widely present. All criteria for considering $D$. sibiricus a potential quarantine pest are met, but the pest is presently absent from EU, and the criteria for consideration as a potential regulated, non-quarantine pest are not met (EFSA 2018).

\section{Identification of human mediated pathways for entry}

The potential pathways for entry of $D$. sibiricus are by human mediated spread and by natural spread. The three human mediated pathways for entry of the pest considered in this PRA are: Living coniferous trees, coniferous wood in the rough, and foliage and branches.

\section{Living coniferous trees}

The probability of entry of $D$. sibiricus with import of the commodity "Living coniferous trees" is considered as unlikely with a medium level of uncertainty.

During the past 30 years, there has been no import to Norway of trees for planting of Abies spp., Larix spp., Picea spp. and Pinus spp. from Russia. However, during the past 20 years there have been small numbers of coniferous plants (unknown species) shipped to Norway from China. There has been no recent import of coniferous trees from Russia to Sweden, and only 12.4 metric tons of coniferous trees has been exported from Russia to Finland during recent years (Eurostat 2017).

\section{Coniferous wood in the rough}

The probability of entry of $D$. sibiricus with import of the commodity "Coniferous wood in the rough" to Norway is considered as unlikely with a medium level of uncertainty.

There have been substantial import of the commodity "Coniferous wood in the rough" (trade code 44.03) from Russia to Norway during the past 30 years, but the import has declined since 2000, and from 2016 there has been no import (Fig. 2). If containing bark these products may carry eggs, larvae and imago of the pest. The category with the highest volume, "Wood for pulping of spruce or other coniferous species" (trade code 44.03.2006) sums up to 1.508 .417 metric tons over 16 out of 20 years and peaked in 1999 (Fig. 2). The category, "Coniferous sawn wood" (trade code 44.03.2001) adds up to 1.136 .599 metric tons over 16 years and peaked in 2000. The category "Wood for pulping" (trade code 44.03.2009) sums up to 127.687 metric tons over 


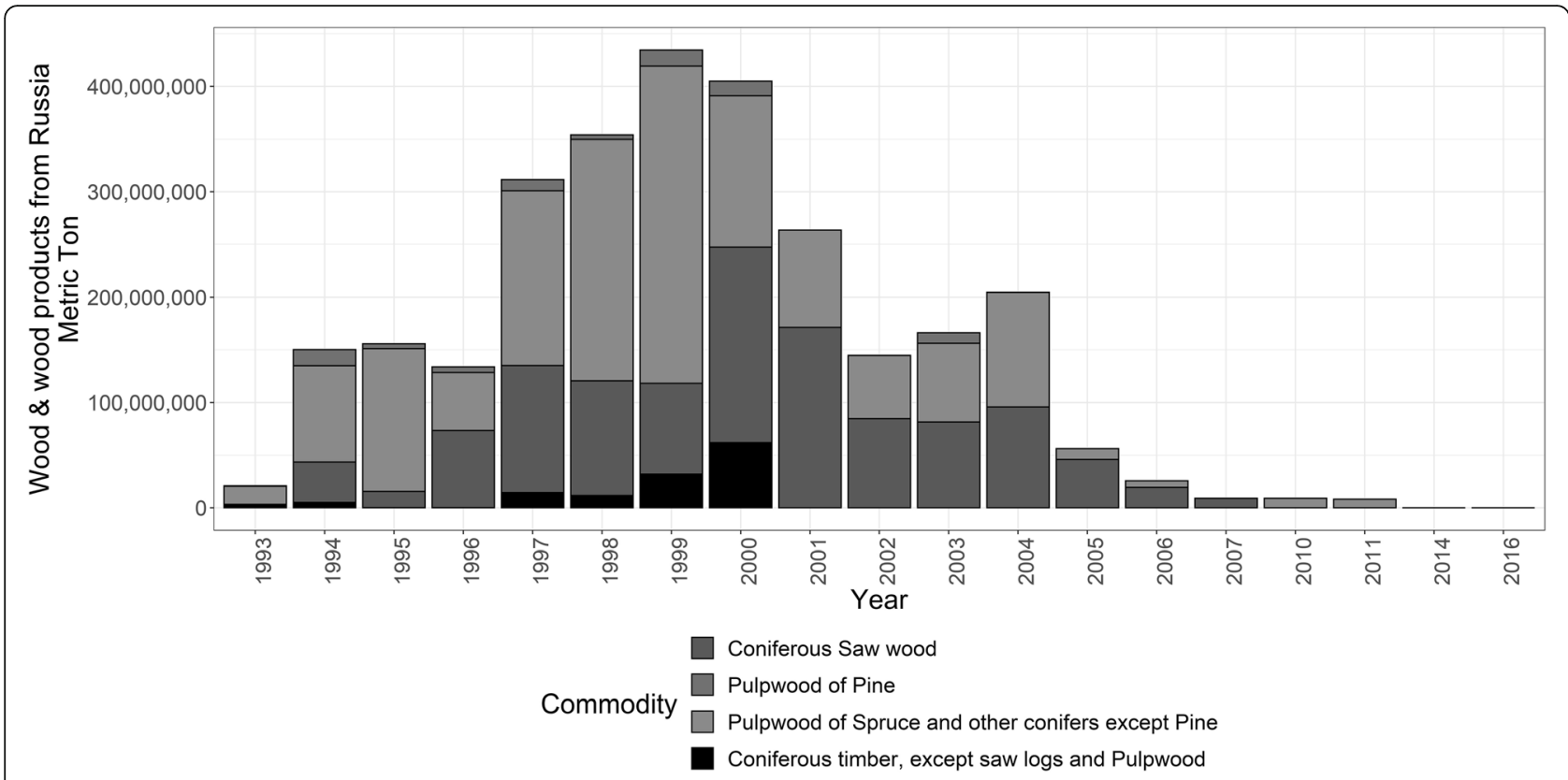

Fig. 2 Amounts (metric tons) of coniferous wood and wood products in the rough (trade code 44.03) imported during the past 30 years from Russia. Data from Statistics Norway (SSB, 2017)

12 out of 20 years and peaked in 2000, and "Wood for pulping of pine" (trade code 44.03.2005) sums up to 80.068 metric tons over 12 out of 20 years and peaked in 1994 (Fig. 2). During the last years, only 0.67 metric tons of "Coniferous sawn wood" (trade code 44.03.2001) were imported from Japan to Norway in 1992. Some of the sub-categories of trade code 44.03 may have contained Abies spp., Larix spp., Picea spp., or Pinus spp. The custom statistics do not reveal the origin of the respective commodities within Russia.

Trade in conifer products with bark from European Russia is not regulated in the same way as is trade from countries outside Europe. This is of concern, since European Russia includes several climate types and ecoregions, potentially harboring a number of unwanted species. Especially, the import of coniferous wood with bark, originating east of the Ural Mountains (approximately 60th meridian east), represents a considerable risk for entry of $D$. sibiricus. The decline and cessation of timber imports from Russia during the last decades may reflect a declining paper and pulp industry in Norway. The import of relevant commodities have shown high variability in the past. In some cases, the volume of a commodity has changed more than $100 \%$ from 1 year to the next (Økland et al. 2012).

\section{Foliage and branches}

The probability of entry of $D$. sibiricus with import of coniferous foliage and branches to Norway is considered as unlikely with a high level of uncertainty.
The commodity "Foliage, branches and other parts of plants" may include coniferous wood with bark and other coniferous items that can host $D$. sibiricus. However, only a small volume of "Foliage, branches and other parts of plants" (‘0.5 metric tons) entered the PRA-area from Russia in 1998, and since then there has been no import of these commodities from Russia in 1998 (Fig. 2).

\section{Natural spread as pathway for entry of the pest}

The probability of natural spread as pathway for entry of D. sibiricus is considered as unlikely with a medium level of uncertainty.

Dendrolimus sibiricus is not expected to spread naturally from its current Western distribution limit in Russia to Norway within the next couple of decades. In a worst-case scenario, where D. sibiricus spreads westwards from Moscow at a rate of $50 \mathrm{~km}$ per year (EPPO 2005), it would take more than 30 years for the species to reach Norway. Natural spread of $D$. sibiricus from the Moscow region to Norway would probably require the insect to fly north of the Gulf of Bothnia.

Based on the current data, it is difficult to conclude that there is no westward movement of the species. However, historical observations indicate that the westward spread may be very slow or non-existent. Dendrolimus sibiricus has probably been present in the Urals since the late nineteenth century or early twentieth century, without expanding westwards (Mikkola and Ståhls 2008). Petersen (1909) judged the western limit of distribution of $D$. sibiricus to be at the 59th meridian east, 
while Eversmann (1844) and Mikkola and Ståhls (2008) reported it to be at the 58th and 56th meridian east, respectively. According to Gninenko and Orlinskii (2002), D. sibiricus is found in the regions of Perm and Udmurtiya, around 52th meridian east. Rozhkov (1963) and Koltunov et al. (1997) judged the western limit of $D$. sibiricus to be approximately at the 52th meridian east. However, Okunev (1955) reported D. sibiricus as far west as the 38th meridian east.

The estimated westward spread of $50 \mathrm{~km} /$ year for $D$. sibiricus, reported by EPPO (2005) and by Möykkynen and Pukkala (2014) was probably based on the assumption that $D$. sibiricus is present in the Moscow area, which is not considered as a valid basis in the present assessment. There were no citations or calculations given for the dispersal estimat of $50 \mathrm{~km} /$ year by these authors.

Baranchikov et al. (2006) maintained that D. sibiricus is not present in the Republic of Mari El (47th meridian east). However, according to Oleg A. Kulinich (personal communication), Russian NPPO in 2016 registered $D$. sibiricus in the Republic of Mari El, in the Republic of Chuvash (approximately 47th meridian east) and in the Kirov region (50th meridian east) (Fig. 1). To our knowledge $D$. sibiricus has never been recaptured in the Moscow oblast or west of Moscow, during the 16 years since the first peste reported findings by Gninenko and Orlinskii (2002).

In agreement with Mikkola and Stahls (2008) and Baranchikov et al. (2006), the conclusion is that the natural westward spread of $D$. sibiricus in European Russia is very slow or non-existent.

\section{Probability of the pest being associated with the pathways}

The overall probability of the pest being associated with the pathways is considered as very likely with high uncertainty.

For the pathway "Coniferous wood in the rough" it is probable that under non-outbreak conditions the pest occurrence has low density throughout the area of distribution during the summer. Therefore, during logging it is impossible to distinguish between trees infested with D. sibiricus larvae and non-infested trees. However, imago, larvae and cocoons will not be present when logging during the winter since overwintering larvae hibernate in the ground, in the soil and under litter.

Regarding the commodities "Living coniferous trees" and "Foliage and branches" the pest occurrence may be at a low density throughout the area of distribution during the summer. In addition, the pest could be present in the soil during the winter in immediate proximity to the trees.
Probability of pest survival during transport and storage The overall probability of the pest to survive during transport and storage is moderately likely with high uncertainty.

The highest probability of survival of $D$. sibiricus is in the commodities "Living coniferous trees" and "Foliage, branches and other parts of plants", because these commodities are handled more carefully and are transported in protected consignments. For the commodity "Coniferous wood in the rough", eggs, larvae, cocoons and imago would be vulnerable to physical and environmental stresses during transport and storage, as these stages live on needles and branches of the trees and may easily be crushed during transport and storage. The commodity "Coniferous wood in the rough" are cut trees without any needles and branches and, therefore, might be less suitable for survival of the larvae and imago.

There are no commercial procedures applied to any of the above-mentioned commodities that would decrease the probability of survival during transport or storage, if phytosanitary measures are not applied.

\section{Probability of pest surviving existing pest management procedures}

The overall probability of the pest to survive existing pest management procedures is unlikely with medium uncertainty.

Import into Norway of plants, wood with bark and chips of wood with bark, isolated bark and wood waste of Coniferales from Non-European countries and Portugal is prohibited (Norwegian Ministry of Agriculture and Food 2018). Dendrolimus sibiricus is included in the EU Plant Health Legislation by EU Directive 2000/29 Annex I/AI, requiring a phytosanitary certificate issued by Russia, ensuring that plants and plant products are inspected and free from D. sibiricus (Council Directive 2000/29/EC 2000).

\section{Probability of transfer to a suitable host}

The probability for the pest to transfer to a suitable host is likely with low uncertainty.

Both wood in the rough and plants for planting arrive all year round, and these commodities are usually stored outdoors. Therefore, with its flight ability $D$. sibiricus will be able to reach suitable hosts.

\section{Conclusions on the probability of entry}

In conclusion, the probability of entry of $D$. sibiricus from areas outside of the PRA area to a suitable habitat within the PRA area is considered as unlikely with a medium level of uncertainty.

The assessment behind this conclusion is that the overall probability of entry by human mediated pathways is unlikely with a medium level of uncertainty. The 
probability of natural spread as a pathway for entry of $D$. sibiricus to the PRA area is unlikely with medium uncertainty, while the rating of the probability of natural spread as an entry of D. sibericus to the PRA-area is very unlikely with low uncertainty.

\section{Probability of establishment in the PRA area}

Climate suitability The establishment of $D$. sibirica in the climate of the PRA area is moderately likely with high uncertainty.

Möykkynen and Pukkala (2014) concluded that the climate in central and northern Europe is favourable for establishment of $D$. sibiricus. The basis for their analysis was a CLIMEX model originally parameterised by Flament et al. (2013). However, in the latter study, the authors based the parameter fitting partly on the map "Siberian moth distribution and areas of injuries", drawn by Rozhkov (1963), except for the mapped western distribution limit. This seems to be a key assumption with respect to the results of Flament et al. (2013) for the projected distribution for $D$. sibiricus concerning the risk of establishment in the PRA area of Norway. While Rozhkov (1963) focused on areas of injuries, Flament et al. (2013) was more focused on the potential geographical distribution of the organism.

The CLIMEX model does not consider the effect of snow cover. For a species having a strategy of overwintering on the ground, or below ground, the CLIMEX model will have important shortcomings with respect to predicting the actual climatic conditions that ground dwelling, or below ground dwelling species, experience in areas with regular snow cover during the winter. Therefore, the CLIMEX model developed by Flament et al. (2013) is not able to predict winter survival for $D$. sibiricus outside its current distribution. In addition, Baranchikov et al. (2010) assessed the potential distribution of $D$. sibiricus by applying a bioclimatic model, and they concluded that the potential for distribution is more constrained than Flament et al. (2013) suggested. Milder winter conditions in European Russia than in Siberia may be a limiting factor, as successful overwintering of larvae requires continuous, continental-type winters. A large part of Siberia is climatically suitable for D. sibiricus by Baranchikov et al. (2010), and the potential distribution closely matches the existing distribution of the pest in Siberia. However, for both studies the supporting information on presence/absence data is very sparse. Baranchikov et al. (2006) questioned the theory that the limited distribution of $D$. sibiricus west of the Ural Mountains is due to mild winters. The current distribution areas of $D$. sibiricus have a more continental climate, (monthly maximum temperatures minus monthly minimum temperatures), i.e. a higher temperature change over the course of the year (Fig. 3) and less precipitation (Fig. 4) than the PRA-area (Kharuk and Antamoshkina 2017). Even in the far east of Russia, where $D$. sibiricus is present to the city of Vladivostok on the Pacific coast, the climate is dominated by cold, dry winters and warm summers with low precipitation.

Dendrolimus sibiricus outbreaks are associated with high summer temperatures (Fig. 5) and low precipitation during the summer, causing drought (Fig. 4). This is similar to the climate requirements of the European species D. pini (Haynes et al. 2014). Drought stress has been shown to lower the quantity of defensive compounds in the host trees, which make the trees more susceptible to attack (Netherer et al. 2015). In proximity to the oceans, trees experience a more humid climate with milder winters, less extreme temperature fluctuations and less drought than in continental climates. Successful overwintering of $D$. sibiricus larvae requires continuous winters of a continental type with no autumn thaws, as temperature fluctuations are fatal for the larvae (Baranchikov et al. 2010). Therefore, stable sub-zero winter temperatures are probably important for the $D$. sibiricus larvae (Fig. 6).

\section{Natural enemies}

Telenomus tetratomus Kieffer 1906 is an important insect egg parasitoid, which regulates the population densities of several insect species in Russia under nonoutbreak conditions (EPPO 2005). This species is also present in Norway, where it attacks D. pini eggs (Adolfsson 1984). In Scandinavia, there are several other species of parasitoids on D. pini some of which may also attack D. sibiricus (Adolfsson 1984), There are large numbers of parasitoides attacking D. sibiricus in Russia (EPPO 2005), and some of these may be present in Norway.

\section{Conclusion on the probability of establishment}

The probability of $D$. sibiricus establishment in the PRA area is unlikely with medium uncertainty.

The PRA area has two potential hosts, Picea abies and Pinus sylvestris, both of which are widely distributed within the country. However, these species are regarded as intermediate and poor hosts, respectively. In addition, most of the PRA-area has a suboptimal environmental condition, with winter temperatures that are not sufficiently cold and with too much precipitation in the summer to allow establishment. The potential of $D$. sibiricus to adapt to new environments is unknown. However, the life cycle of the pest is dynamic, which may be beneficial for adaption to new and adverse conditions. Dendrolimus sibiricus has never been intercepted outside its main area of distribution, and in Russia there is no or very slow speed westwards. There are currently no import of 


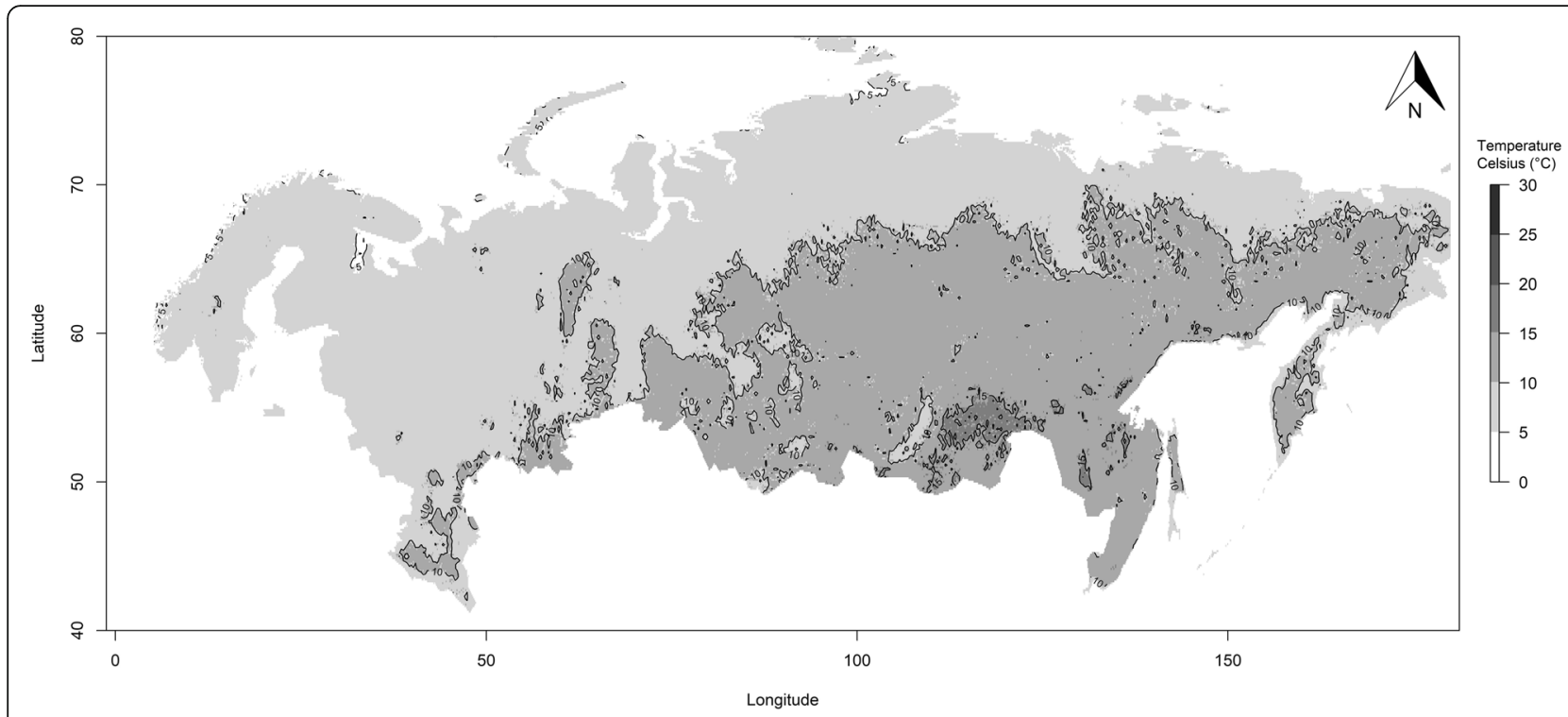

Fig. 3 A map of Russia, Finland, Sweden and Norway showing continentally (monthly maximum temperature minus monthly minimum temperature $\left.\left({ }^{\circ} \mathrm{C} * 10\right)\right)$

commodities that could support entry of $D$. sibiricus into the PRA-area.

\section{Probability of spread after establishment}

The probability of $D$. sibiricus spread after establishment in the PRA area is likely with high uncertainty.

The exact flight capacity of $D$. sibiricus is unknown, but its behaviour probably depends on the density of suitable host trees, where the pest will seek out the nearest suitable host. However, D. sibiricus adults are strong flyers, and they are reported to fly up to $100 \mathrm{~km}$ per year (EPPO 2005). Wind direction and wind strength will strongly affect the spread of the moths. In addition, the movement of the commodities: "Living coniferous trees", "Wood in the rough" and "Foliage or branches" may further aid long-distance spread after establishment.

\section{Endangered area within the PRA area}

The part of the PRA area, where ecological factors may be favourable for establishment, are the areas with the

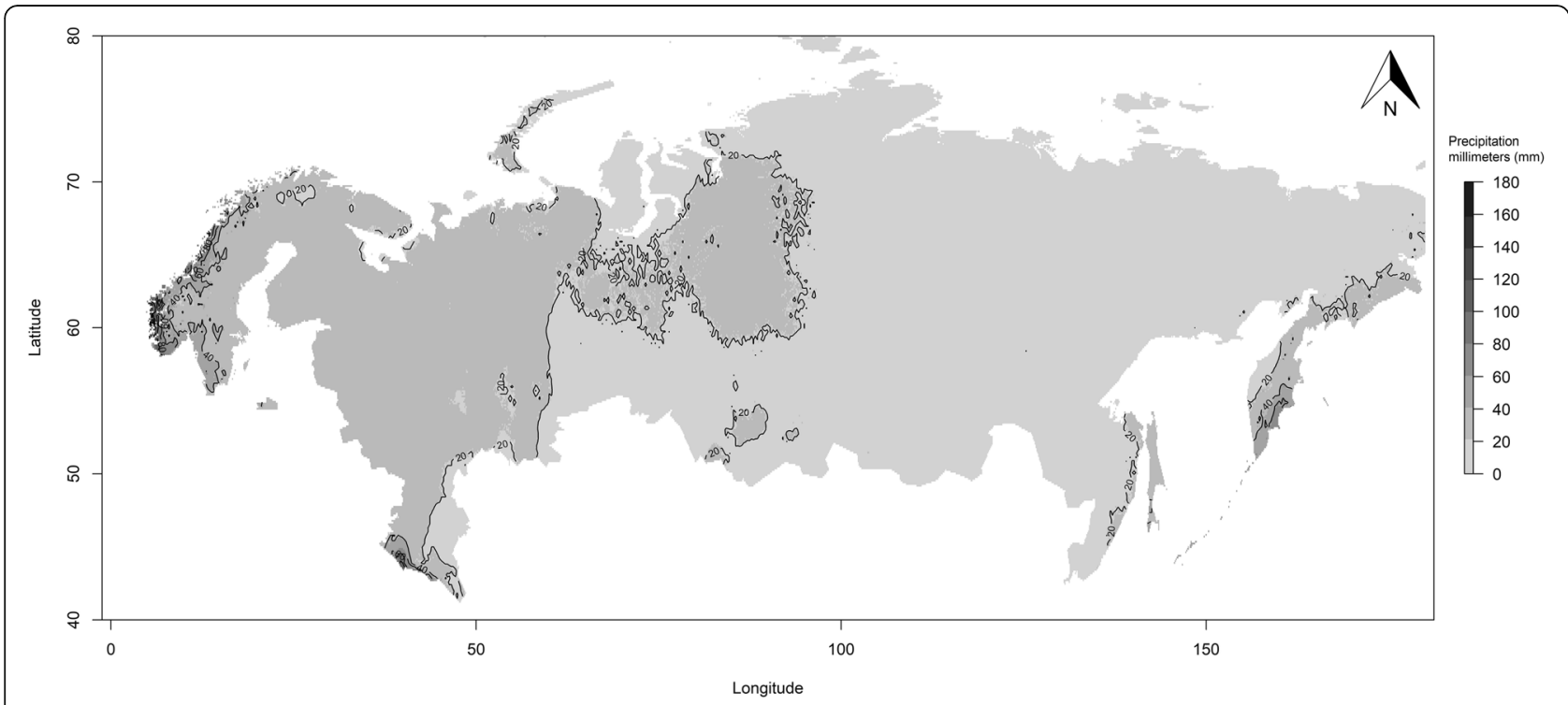

Fig. 4 Precipitation during the driest month of the year (August) shows that the total precipitation (millimeters), is lower East of the 60th meridian, and that precipitation is much higher in parts of the PRA-area 


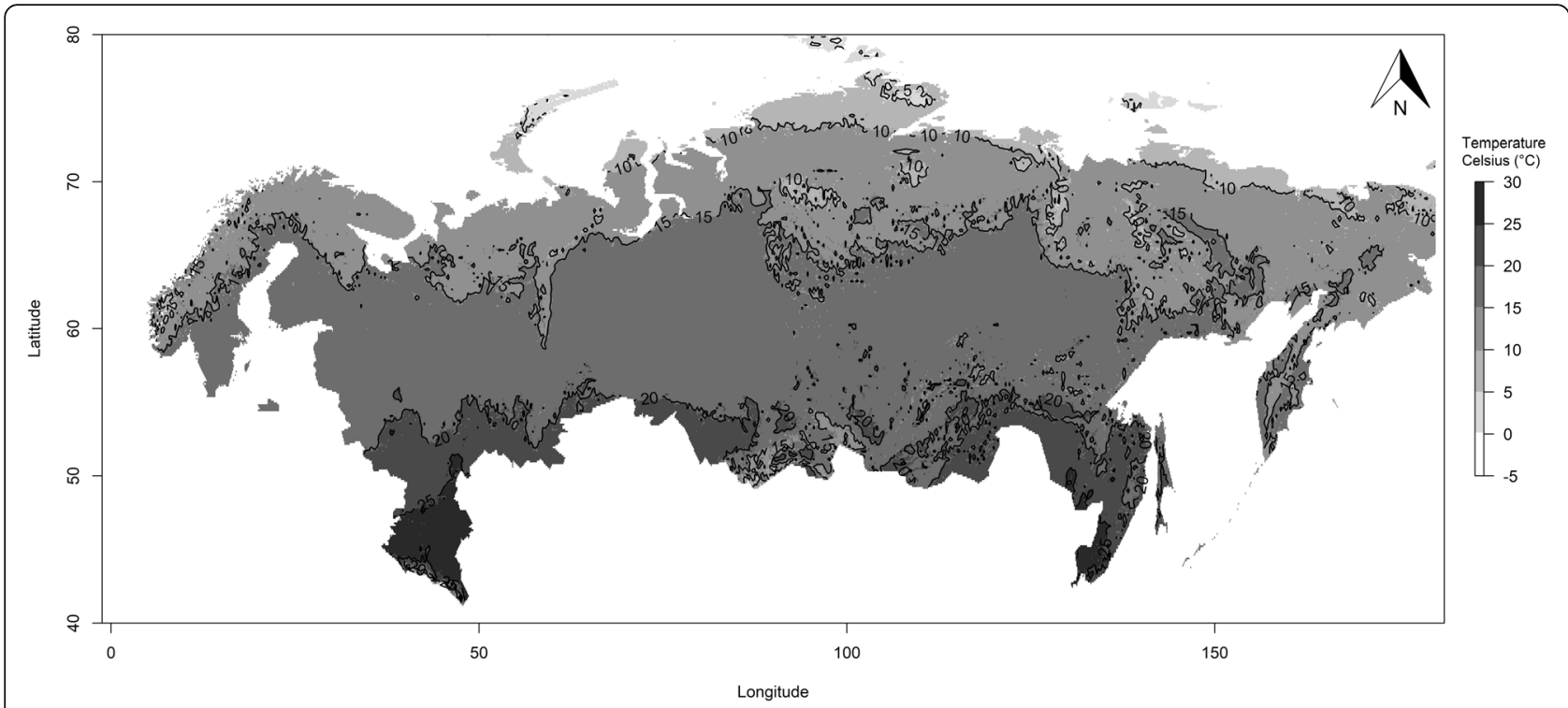

Fig. 5 The maximum temperatures $\left({ }^{\circ} \mathrm{C}\right)$ of August, the warmest month (30 year normal), are generally similar, where Dendrolimus sibiricus is present, but higher in parts of the PRA-area

coldest and continuous winters, and the warmest and driest summers. This includes the areas furthest away from the moderating effects of the Atlantic Ocean, which are the counties of Akershus, Hedmark, Oppland, and possibly inner parts of Finnmark.

\section{Assessment of impact}

Dendrolimus sibiricus is among the most important defoliators and the most destructive pests of conifers in its natural habitat in Russia. In the period from 1994 to 1996, D. sibiricus damaged 700.000 ha of pine forest in the Krasnoyarsk krai (Zhirin et al. 2016), and between 1954 and 1957 the pest killed over 1.5 million hectares of pine near the Ket and Chulym rivers (Kharuk et al. 2016). During a period of 25 years, between 1932 and 1957, D. sibiricus damaged 7 million hectares of forest and killed $50 \%$ of the trees in West Siberia and Chita Oblast in South East Siberia (Baranchikov and Montgomery 2014, EPPO 2005). In China, D. sibiricus is

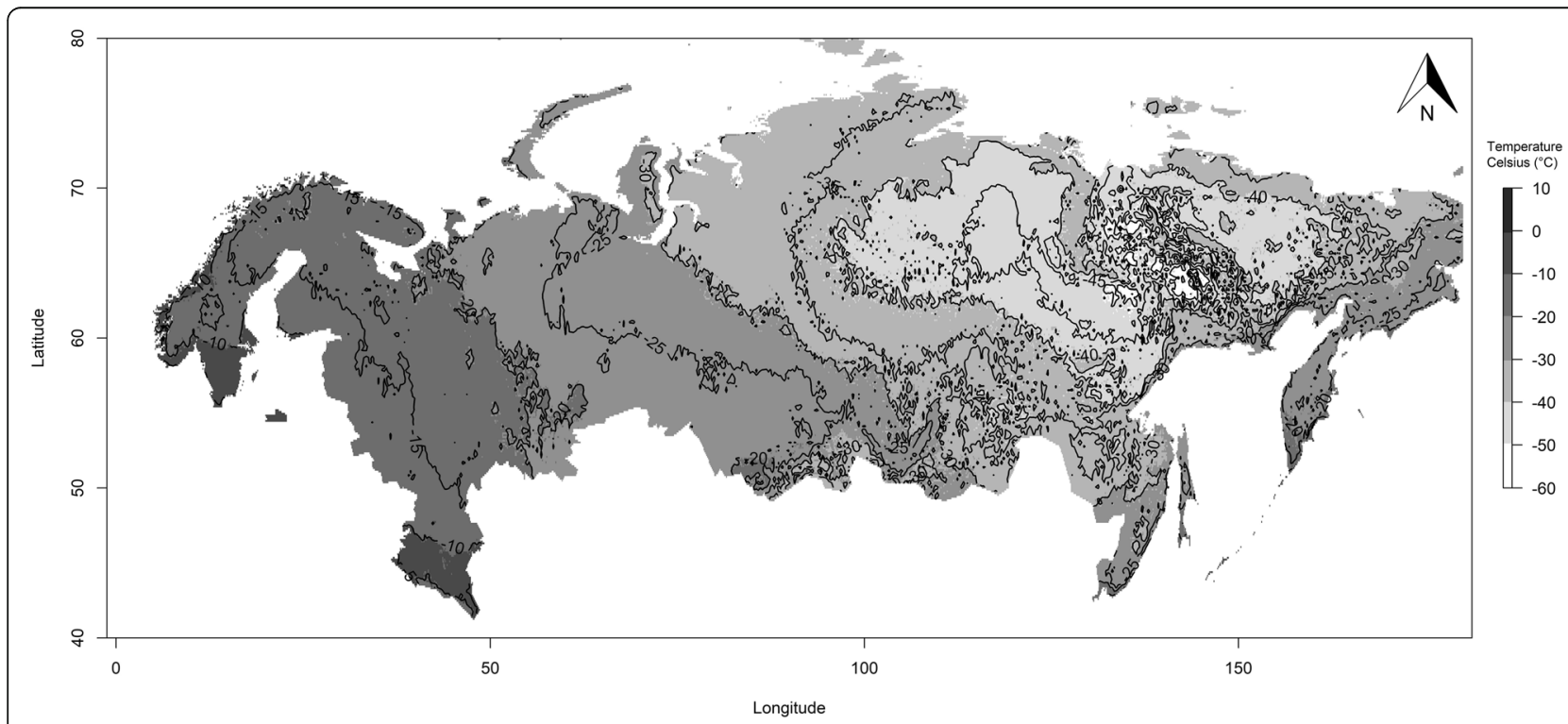

Fig. 6 The minimum temperatures $\left({ }^{\circ} \mathrm{C}\right)$ of January, the coldest month (30 year normal), are generally lower, where Dendrolimus sibiricus is present, than in the PRA-area 
considered a major defoliator of the Dahurian larch, Larix gmelinii (Rupr.) Kuzeneva (EPPO 2005).

Continuous defoliation by $D$. sibiricus may cause death of forests over large areas, either directly or by leaving forests prone to subsequent attacks by other forest pests, such as woodborers in the families Scolytidae and Cerambycidae (EPPO 2005). In addition, outbreaks may make the forests more predisposed to forest fires (EPPO 2005). The reestablishment of forests after an outbreak is complicated (EPPO 2005), and consequently the attack may lead to major changes in the environment and biodiversity.

In bioassay experiments with $D$. sibiricus, the two Norwegian potential hosts, $P$. abies and $P$. sylvestris, were described as intermediate and poor hosts, respectively (Kirichenko et al. 2011). However, it is unknown how severe the impact would be under Norwegian climatic conditions, which are regarded as suboptimal. Severe damage caused by outbreaks of $D$. sibiricus in Norway would probably require several years of drought stressed host trees, similar to the circumstances observed during the latest outbreaks of $D$. pini in Hedmark County during 1812-1816 and 1902-1904. Interactions between $D$. sibiricus and $D$. pini could possibly result in more severe outbreaks than those caused by $D$. pini alone.

\section{Conclusion on the impact}

It is unlikely that $D$. sibiricus will have an impact in the near future within the PRA area. Therefore, there will be no economic consequences from an introduction of the pest. This is an assessment with a high uncertainty.

\section{Risk reduction options to prevent entry and establishment}

The existing phytosanitary requirements by EPPO, as stated in the commodity-specific phytosanitary measures are regarded as highly applicable for reducing the risk of introduction of D. sibiricus into Norway (EPPO 2005). The option "Pest-free areas for D. sibiricus" is problematic, since the true distribution of the pest is uncertain in the European part of Russia.

EPPO (2005) recommended that to prevent the introduction of $D$. sibiricus through international movement of commodities, plants for planting and cut branches of host plants from infested areas should be free from soil. Alternatively, such commodities should originate in a pest free area, be produced in protected houses, fumigated or imported during the winter. Wood should be debarked or heat-treated, originate in a pest free area or be imported during the winter, and isolated bark should be treated to destroy contaminating insects.

Any import of Abies spp., Larix spp., Picea spp. and Pinus spp. from areas in Russia, where $D$. sibiricus is present, may result in high probability of entry of the $D$. sibiricus, since egg clusters, larvae and imago may be present on branches and stems of the trees.

In current Norwegian regulations (Norwegian Ministry of Agriculture and Food 2018) four specific provisions concerning import of plants are described.

Import of Coniferales plants, wood with bark, chips of wood with bark, isolated bark and wood waste of Coniferales from Non-European countries and Portugal is prohibited. Import of wood chips from Canada, China, Japan, Korea, Mexico, Portugal, Taiwan and USA is prohibited.

Consignments containing plants and other regulated articles shall on import be accompanied by phytosanitary certificate for export.

\section{Management options to prevent spread following entry}

Dendrolimus sibiricus is not regulated in Norway, but the species is on the current "ЕPPO A2 list of pest recommended for regulations as quarantine pests" (EPPO 2017). Regulation of the pest to limit import of host plant commodities to pest free areas will reduce the risk for entry of the pest.

Demarcated zones and buffer areas should be established as soon as possible following an outbreak. The Forestry Commission of the United Kingdom recommends regulated zones with at least $10 \mathrm{~km}$ radius around infested trees (Poulsom 2016).

There are currently no pesticide approved for insect control in Norwegian forests. With restrictions, similar to the currents regulations on chemical weed control in forests, the effect of pesticide application on an outbreak of D. sibiricus in Norwegian forests would be very limited.

\section{Discussion}

The import from Russia of commodities that are potential hosts for D. sibiricus has declined during the last 20 years, and there has been no import of these commodities into Norway during the last 5 years. Even though this trend indicates a cessation in import along relevant pathways, attention should be focused on future development of import from other areas where D. sibiricus is present.

Trade in conifer products with bark from European Russia is not regulated in the same way as trade from countries outside of Europe. This is of concern, since European Russia includes several climate types and ecoregions, potentially harboring a number of unwanted species. Especially, the import of coniferous wood with bark originating from the east of the Ural Mountains represents a considerable risk for the entry of $D$. sibiricus.

The import of relevant commodities has shown high variability in the past. In some cases, the volume of a 
commodity has changed more than 100\% from 1 year to the next (Økland et al. 2012). This large temporal variation in imports from Russia has also been observed in other European countries, where timber imports from Russia had a dramatic increase in the 1990s, but since the turn of the century imports changed in time and in area of origin (Piel et al. 2008). The reduction of timber imports from Russia during the last decade may reflect a declining paper and pulp industry in Norway. Even though this trend indicates a cessation in import along relevant pathways, attention should be focused on future import from areas where $D$. sibiricus is present.

\section{Acknowledgements}

We would like to thank VKM penal members Guro Brodal, Åshild Ergon, Christer Magnusson, Arild Sletten and Halvor Solheim for their contribution to the initial pest risk assessment of Dendrolimus sibiricus and Dendrolimus superans.

\section{Authors' contributions}

DF and LS wrote the first draft; all authors contributed critically to successive drafts and gave final approval for publication.

\section{Funding}

This research received no funds. However, the initial pest risk assessment of Dendrolimus sibiricus and D. superans, witch this review is based upon, was founded by The Norwegian committee for food and environment.

\section{Availability of data and materials}

Not applicable.

\section{Ethics approval and consent to participate}

Not applicable.

\section{Consent for publication}

Not applicable.

\section{Competing interests}

The authors declare that they have no competing interests.

Received: 8 November 2019 Accepted: 2 July 2020

Published online: 27 July 2020

\section{References}

Adolfsson J (1984) Tallspinnaren och dess parasitoider - ett kansligt samspel i skogen. Ent Tidsskr 105:15-24 (in Swedish)

Baranchikov YN, Montgomery ME (2014) Chapter XXXVI. In: Siberian Moth, the use of classical biological control to preserve forests in North America, pp 383-391

Baranchikov YN, Pet'ko VM, Ponomarev VL (2006) The Russians are coming-aren't they? Siberian moth in European forests, Proc 17th U.S. Department of Agriculture - Interagency Research Forum on Gypsy Moth and other Invasive Species. GTR-NRS-P-10, pp 18-20

Baranchikov YN, Tchebakova N, Kirichenko N, Parphenova E, Korezts M, Kenis M (2010) Chapter 6. Biological invasions: the Siberian moth, Dendrolimus superans sibiricus, a potential invader in Europe? In: Settele J et al (eds) Atlas of biodiversity risk. Pensoft Publishers, Bulgaria, p 158

Council Directive 2000/29/EC (2000) On protective measures against the introduction into the community of organisms harmful to plants or plant products and against their spread within the community. http://data.europa. eu/eli/dir/2000/29/oj

EFSA PLH Panel (2018) Pest categorisation of Dendrolimus sibiricus. EFSA J 16(6): 5301. https://doi.org/10.2903/j.efsa.2018.5301

Elven R (2005) Norsk flora. Det norske samlaget, p 1230 (in Norwegian)

EPPO (1998) Pest risk analysis to decide immediate action to be taken on interception of a pest in an EPPO country: Dendrolimus sibiricus 99/7075
EPPO (2000) Pest risk assessment: Dendrolimus sibiricus Tschetverikov (Lepidoptera: Lasiocampidae), p 16 00/8481

EPPO (2005) Data sheets on quarantine pests: Dendrolimus sibiricus and Dendrolimus superans. EPPO Bull 35:390-395. https://doi.org/10.1111/j.13652338.2005.00878.x

EPPO (2017) EPPO A2 list of pests recommended for regulation as quarantine pests, $\mathrm{p} 18$

Eurostat. (2017). Retrieved from. http://ec.europa.eu/eurostat/web/main/home. Accessed Aug 242017.

Eversmann E (1844) Fauna lepidopterologica volgo-uralensis. Typis Universitatis, Casani, p 633

Flament J, Kriticos DJ, Kirichenko N, Baranchikov YN, Grégoire J-C (2013) Projecting the potential geographical distribution of the Siberian moth Dendrolimus sibiricus, using the CLIMEX model

Gninenko YI, Orlinskii AD (2002) Dendrolimus sibiricus in the coniferous forests of European Russia at the beginning of the twenty-first century. EPPO Bull 32(3): $481-483$

Hardin JA, Suazo A (2012) Dendrolimus pine moths, new Pest response guidelines. United States Department of Agriculture 12/2012-01

Haynes KJ, Allstadt AJ, Klimetzek D (2014) Forest defoliator outbreaks under climate change: effects on the frequency and severity of outbreaks of five pine insect pests. Glob Change Biol 20:2004-2018. https:/doi.org/10.1111/ gcb.12506

Kharuk VI, Antamoshkina OA (2017) Impact of Silkmoth outbreak on taiga wildfires. Cont Probl Ecol 10:556-562. https://doi.org/10.1134/ S1995425517050055

Kharuk VI, Demidko DA, Fedotova EV, Dvinskaya ML, Budnik UA (2016) Spatial and temporal dynamics of Siberian silk moth large-scale outbreak in darkneedle coniferous tree stands in Altai. Cont Probl Eco 9:711-720. https://doi. org/10.1134/S199542551606007x

Kirichenko N, Flament J, Baranchikov Y, Gregoire JC (2011) Larval performances and life cycle completion of the Siberian moth, Dendrolimus sibiricus (Lepidoptera: Lasiocampidae), on potential host plants in Europe: a laboratory study on potted trees. Eur J Forest Res 130:1067-1074. https://doi. org/10.1007/s10342-011-0495-3

Kirichenko NI, Baranchikov YN, Vidal S (2009) Performance of the potentially invasive Siberian moth Dendrolimus superans sibiricus on coniferous species in Europe. Agric Forest Ent 11:247-254. https://doi.org/10.1111/j.1461-9563. 2009.00437.x

Koltunov EV, Si F, Ov O (1997) Dendrolimus sibiricus in the spruce-fir forests of the plains east of the Urals. Lesnoe Khozyaistvo 2:51-52 (In Russian)

Kononov A, Ustyantsev K, Wang B, Mastro VC, Fet V, Blinov A, Baranchikov Y (2016) Genetic diversity among eight Dendrolimus species in Eurasia (Lepidoptera: Lasiocampidae) inferred from mitochondrial COI and COII, and nuclear ITS2 markers. BMC Genet 17:157. https://doi.org/10.1186/s12863-0160463-5

Kubasik W, Klejdysz T, Gawlak M, Czyż M, Olejniczak A, Kałuski T (2017) Analizy Zagrożenia Agrofagiem (Ekspres PRA) dla Dendrolimus sibiricus. Rzeczpospolita Polska, Institute of Plant Protection-NRI Poznan, Poland

Mikkola K, Ståhls G (2008) Morphological and molecular taxonomy of Dendrolimus sibiricus Chetverikov stat.Rev. and allied lappet moths (Lepidoptera : Lasiocampidae), with description of a new species. Ent Fennica 19:65-85

Möykkynen T, Pukkala T (2014) Modelling of the spread of a potential invasive pest, the Siberian moth (Dendrolimus sibiricus) in Europe. Forest Ecosyst 1:10. https://doi.org/10.1186/s40663-014-0010-7

Netherer S, Matthews B, Katzensteiner K, Blackwell E, Henschke P, Hietz P, Pennerstorfer J, Rosner S, Kikuta S, Schume H, Schopf A (2015) Do waterlimiting conditions predispose Norway spruce to bark beetle attack? New Phytol 205:1128-1141. https://doi.org/10.1111/nph.13166

Norwegian Ministry of Agriculture and Food (2018) Regulations related to plants and measures against pests, $\mathrm{p} 78$

Økland B, Børja I, Often A, Solheim H, Flø D (2012) Import av tømmer og andre treprodukter som innførselvei for fremmede insekter, sopp og planter - trendanalyse av importstatistikk, Rapport fra Skog og landskap (10) 137s. Norsk institutt for skog og landskap, Ås http://hdl.handle. net//11250/2453914

Okunev PP (1955) Geographical distribution and zones of injuriousness of Dendrolimus sibiricus. Geogr Probl For 5:32-48 
Petersen W (1909) Preliminary report on the trip for the study of Lepidoptera and their spread along the Ural mountain ridge in 1903. In: News of the Russian Imperial Geographical Society, vol 11

Piel F, Gilbert M, De Canniers C, Gregoire JC (2008) Continous round wood imports from Russia and Baltic countries to Belgium. A pathway analysis for assessing the risks of exotic pest insect introduction. Divers Distrib 14:318328. https://doi.org/10.1111/j.1472-4642.2007.00390.x

Poulsom L (2016) Contingency plan for the Siberian coniferous silk moth (Dendrolimus sibiricus). Forest Com 11.08.2016, 25 pages

Rafoss T, Flø D, Sundheim L, Wendell M, Brodal G, Ergon Å, Magnusson C, Sletten A, Solheim H, Tronsmo AM (2018) Pest risk assessment of Dendrolimus sibiricus and Dendrolimus superans. In: Opinion of the Panel on Plant Health of the Norwegian Scientific Committee for Food and Environment, p 68 VKM report 2018:08, ISBN: 978-82-8259-305-2, ISSN: 2535-4019

Rozhkov AS (1963) Dendrolimus sibiricus. Izdatel'stvo Akademii Nauk SSSR, Moscow (RU1 63:175) (in Russian)

Zhirin VM, Knyazeva SV, Eydlina SP (2016) Long-term dynamics of vegetation indices in dark coniferous forest after Siberian moth disturbance. Cont Probl Ecol 9:834-843. https://doi.org/10.1134/ S1995425516070118

\section{Submit your manuscript to a SpringerOpen ${ }^{\circ}$ journal and benefit from:}

- Convenient online submission

- Rigorous peer review

- Open access: articles freely available online

High visibility within the field

- Retaining the copyright to your article

Submit your next manuscript at $\boldsymbol{\nabla}$ springeropen.com 